\title{
The riddle of style changes in the visual arts after interference with the right brain
}

\section{Olaf Blanke ${ }^{1,2} *$ and Isabella Pasqualini ${ }^{1,2}$ *}

1 Laboratory of Cognitive Neuroscience, Brain Mind Institute, Ecole Polytechnique Fédérale de Lausanne, Lausanne, Switzerland

${ }^{2}$ Atelier de la conception de l'espace, Institute of Architecture and the City, Ecole Polytechnique Fédérale de Lausanne, Lausanne, Switzerland

\section{Edited by:}

Idan Segev, The Hebrew University of Jerusalem, Israel

Reviewed by:

Stefan Pollmann, Otto von Guericke

University, Germany

Lutz Jäncke, University of Zurich,

Switzerland

\section{*Correspondence:}

Olaf Blanke, Laboratory of Cognitive Neuroscience, Brain-Mind Institute,

Ecole Polytechnique Fédérale de

Lausanne, Station 19, CH-1015

Lausanne, Switzerland.

e-mail: olaf.blanke@epfl.ch;

Isabella Pasqualini, Atelier de la

conception de l'espace, Institute of

Architecture and the City, Ecole

Polytechnique Fédérale de Lausanne,

Station 16, CH-1015 Lausanne,

Switzerland.

e-mail: isabella.pasqualini@epfl.ch
We here analyze the paintings and films of several visual artists, who suffered from a welldefined neuropsychological deficit, visuo-spatial hemineglect, following vascular stroke to the right brain. In our analysis we focus in particular on the oeuvre of Lovis Corinth and Luchino Visconti as both major artists continued to be highly productive over many years after their right brain damage. We analyzed their post-stroke paintings and films, indicate several aspects that differ from their pre-stroke work (omissions, use of color, perseveration, deformation), and propose-although both artists come from different times, countries, genres, and styles-that their post-stroke oeuvre reveals important similarities in style. We argue that these changes may be associated with visuo-spatial hemineglect and the right brain. We discuss future avenues of how the neuropsychological investigation of visual artists with and without neglect may allow us to investigate the relationship between brain and art.

\section{Keywords: visual arts, painting, film, neuropsychology, neurology, Lovis Corinth, Luchino Visconti}

\section{INTRODUCTION}

What is visual art? What are paintings? What are films? Innumerous answers have been proposed to these questions. During the last century despite a notable increase in such endeavors a general agreement on the adequacy of the questions posed or the answers provided has not been attained. Hence, in this text we suggest a different line of questions along with some preliminary answers that highlight the starting point for further investigations on the relationship between the visual arts and the brain.

In the present study we analyze the artworks of several visual artists, who suffered from a well-defined neuropsychological deficit -visuo-spatial hemineglect-following damage to the right brain. What can we learn about art using this approach? What is new in the present approach? And what could this analysis tell us about the relationship between visual arts and the brain? Several authors have applied principles from psychoanalysis (Kris, 1952), Gestalt psychology (Arnheim, 1954), as well as cognitive psychology and neuroscience (Rentschler, 1988; Zeki, 2000) to the visual arts. We here explore how the neuropsychological investigation of visual artists allows deeper understanding of the relationship between brain and art and argue that this approach has several advantages with respect to previous work on art and the brain (Blanke and Ortigue, 2011).

Over the last 150 years neuropsychological studies have led to the description of many important mechanisms of human brain functions such as language, visual and spatial perception, recognition, memory, and motor execution. Yet, these insights have not been applied systematically to the understanding of art, although some investigations on art were carried out by neurologists and neuropsychologists with an amateur interest in the arts such as Bonvicini (1926), Alajounaine (1948), Jung (1974), Gardner (1975), and more recently Vigouroux (1997), Zaidel (2006), and (Blanke and Ortigue, 2011). We agree with Zaidel (2006) that the detailed study of painters with brain damage and its effect on the painters' art is probably the richest and most direct source for the elucidation of the relation between brain and art (as compared to insights based on psychological approaches or neuroscientific approaches, at least at the moment). We also note, that despite the accumulation of several neuropsychological observations in painters with different neuropsychological symptoms due to stroke over the last 100 years, this has not sparked much interest in art history or criticism (but see Cela-Conde et al., 2011; Nadal and Pearce, 2011). We predict that this will change in the future as it has already in the field of philosophy and the social sciences.

The cited neurologists and neuropsychologists have not only analyzed paintings but also have described the effects of brain damage on music and poetry. Whereas these analyses revealed important differences on art making following brain damage in different artistic genres (see the devastating effects of a left hemisphere stroke in Baudelaire and Debussy for example; Alajounaine, 1948), this has not allowed to describe in greater detail the effects of brain damage on the visual arts. Here we have followed and hope to have extended the approach initiated by art connoisseur, painter, and neurologist Richard Jung. He focused on one specific art genre 
-painting-and studied paintings and drawings only in painters suffering from a clearly defined type of disease and brain damage -stroke to the right-hemisphere, associated with the neuropsychological symptom of visuo-spatial hemineglect (visuo-spatial HN; Jung, 1974, 1975; see also Gardner, 1975). Herein we aim to extend the Jungian approach by analyzing the neuropsychology and artwork of two major categories in the visual arts -painting (Lovis Corinth, Anton Räderscheidt, and Huguette Bouchardy-Rey) and film (Federico Fellini and Luchino Visconti). These artists suffered from stroke affecting the right brain associated with visuo-spatial $\mathrm{HN}$. We are well aware that our approach is highly selective (only the visual arts, only some genres from the visual arts, only left-sided spatial HN, only right-hemisphere damage, only neuropsychological analysis), yet we believe that such a concentration is a necessary constraint - at least at the beginning, in order to develop approximate directions and empirical guidelines for this new discipline between neuropsychology and art theory.

\section{VISUO-SPATIAL HEMINEGLECT}

Before detailing the effects of visuo-spatial $\mathrm{HN}$ in painting and film, we briefly introduce neurological, neuropsychological, and graphical signs of visuo-spatial HN. Hemineglect is a common neuropsychological condition following right posterior brain damage and is an attentional disorder characterized by disregard of sensory, imagined, or action information in the part of space to the left of the midline (Robertson and Halligan, 2001; Blanke and Lenggenhager, 2007). Thus, visuo-spatial HN is characterized by an attention deficit that mostly (but not only) concerns those parts of space that are contralateral with respect to brain damage. Typically $\mathrm{HN}$ is associated with right brain damage (leading to left-sided $\mathrm{HN}$ ), particularly damage in right parietal and/or superior temporal cortex (Halligan and Marshall, 2001; Figure 1A), but also to premotor cortex (Verdon and Vuilleumier, 2010). $\mathrm{HN}$ is often associated with left-sided somatosensory and motor deficits that may affect arm and leg. In some cases of extensive and more posterior brain damage, $\mathrm{HN}$ may also be associated with left-sided hemianopia or left lower quadranopia. Language and memory deficits only rarely occur jointly with HN. Although $\mathrm{HN}$ is often associated with left-sided sensorimotor and visual deficits, the attentional deficit is classically independent of sensory or motor deficits. HN patients may thus behave as if the contralesional space did not exist, even if their brain mechanisms for left-sided perception and action are intact (for further discussion with respect to the visual arts see below). In addition, many HN patients are not aware of their left-sided attentional and sensorimotor deficits (i.e. anosognosia), although patients with visuo-spatial HN with and without anosognosia have an impaired ability to orient and react toward objects in contralateral space.

Hemineglect is a complex condition (Kerkhoff, 2001) that may affect different sensory modalities and cognitive functions to different degrees. In brief, neuropsychology distinguishes three major forms of HN: sensory, motor, and representational $\mathrm{HN}$ and these different forms have been associated with damage to different brain regions (Verdon and Vuilleumier, 2010). A deficit to react to stimuli such as visual, auditory, or tactile cues is called sensory HN (Kerkhoff, 2001). Motor HN is characterized by lessened

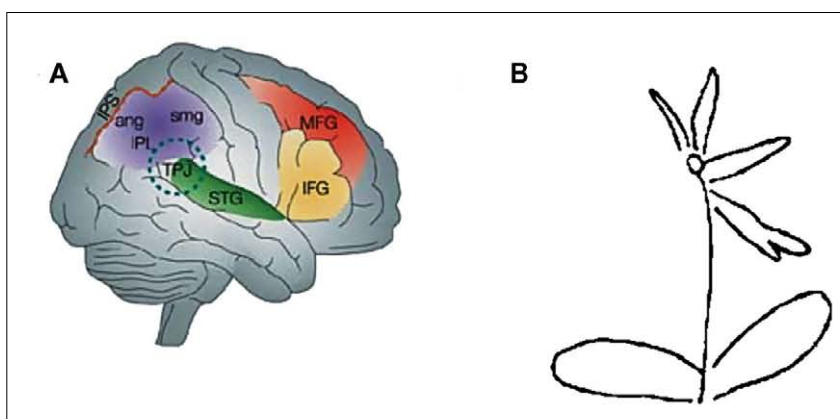

C

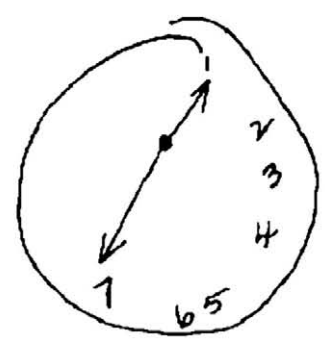

D

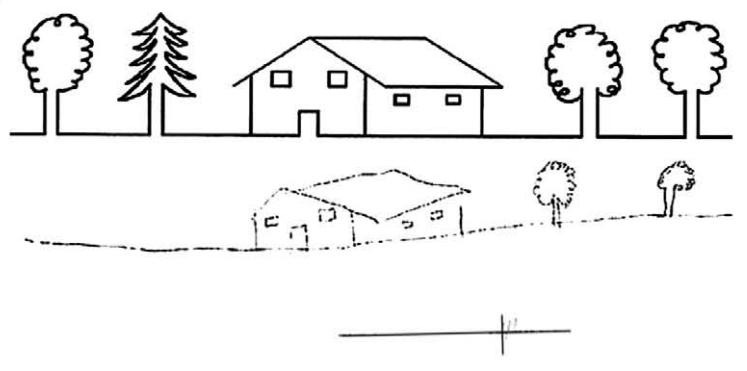

E

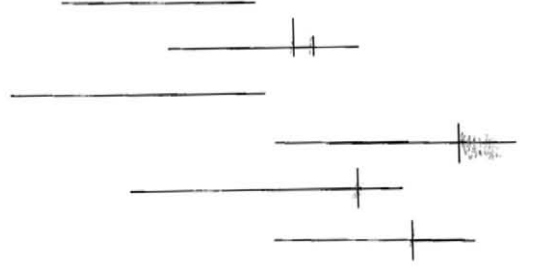

FIGURE 1 | Visuo-spatial hemineglect (HN). (A) Location of brain damage in patients with visuo-spatial HN (after Halligan and Marshall, 2001). (B) Example of object-centered HN. (C) Example of clock test drawing by a patient with HN. (D) Landscape test (top) with example of drawing by a patient with HN. (E) Line bisection task with drawing by a patient with $\mathrm{HN}$ showing rightward deviations and omitted lines on the left.

spontaneous movements (including eye movements) and exploration in the contralateral direction (Kerkhoff, 2001). HN may also be present when patients imagine spatial scenes, even in the apparent absence of sensory or motor HN. This form of $\mathrm{HN}$ is called representational neglect and was described initially when imagining public spaces such as the Piazza del Duomo in Mailand (Bisiach and Luzzatti, 1978; Ortigue et al., 2006). Of further relevance for the present study is the differentiation between objectand space-centered HN. The latter designates a left-sided HN with respect to the horizontal (mid-sagittal) body axis of the patient (omission of items on the left side of a drawing that is positioned 
in front of the patient). Object-centered $\mathrm{HN}$ is characterized by omissions on the left side of a drawn or perceived object that can be positioned on the right or the left side of the paper (Figure 1B).

In order to diagnose visuo-spatial $\mathrm{HN}$, neuropsychologists use several standardized paper and pencil tests that allow the quick and precise detection and quantification of perceptual and graphical elements on HN. We here briefly describe several such tests of relevance for understanding visual art works by artists with visuo-spatial HN. During clinical routine testing several other standardized tests, also including computer-based tests are used to reveal the intensity and the different aspects of $\mathrm{HN}$ (see Robertson and Halligan, 2001). In the clock test the patient is asked to draw a clock from memory or to fill in the clock's numbers into a preexisting circle. $\mathrm{HN}$ patients often draw only the right side of the clock, omit the digits on the left side (7-12) or draw all digits from 1 to 12 into the right half of the circle (Figure 1C). Often a spatial deformation of the drawn clock or perseverations (of clock elements), as well as an altered orientation of the digits may be observed. Copying tests consist of the copying of a complex abstract geometric figure, a daisy, clock, or the drawing of a small landscape with a house and trees (Figure 1D). HN will be perceived in form of omissions on the left side of the sheet and object-centered neglect (by missing details or by deformations on the left of each individual object). Further graphical signs such as loss of perspective, general simplification, changed ductus, repetitions, or perseverations have also been observed (Blanke and Ortigue, 2011). In the line bisection task the patient is asked to indicate the middle of several horizontal lines shown on a piece of paper. Patients who neglect the left side of the line systematically indicate the middle of the line too far on the right side (Figure 1E). This behavior can be observed particularly with long lines or with lines, which are on the left, the contralesional side of the sheet. In cancellation tests, as the "Letter cancelation test" or the "Bell cancelation test" the patient is shown a sheet, on which several letters or bells are being drawn. The patient is asked to find all specific symbols (i.e., the bells) on the whole sheet and to mark them. Patients with left-sided visuo-spatial HN typically omit targets on the left side of the sheet. Below we have focused on visual signs that can be seen in the artworks of selected visual artists with left-sided HN. As previous authors, we have extended the use of clinical tools to the study of artworks and searched for HN signs in paintings, drawings, and films. How is $\mathrm{HN}$ characterized in these different art forms? Do painters and filmmakers continue to make art? Is their art changed? What do these changes look like? As we will see quite a few studies about paintings and painters have already been carried out, but almost no work exists about the effects of $\mathrm{HN}$ on film.

\section{PAINTING}

Over the last century many painters have been described who suffered from visuo-spatial HN due to right hemispheric brain damage. Among them were Lovis Corinth and Otto Dix (Jung, 1974, 1975), Bruno Alder (Schnider et al., 1993), Huguette BouchardyRey (Blanke et al., 2003), Pierre Ambrogiani (Vigouroux et al., 1990), Anton Räderscheidt (Jung, 1974), and many others (Bänzer and Hennerici, 2006; Blanke and Ortigue, 2011). We have here focused on the work of Corinth and further discuss a few works by
Räderscheidt and Bouchardy-Rey. As we will see below the analysis of the work by these three artists who worked during different periods of the nineteenth, twentieth and twenty-first century will allow us to highlight some converging post-stroke style changes, despite prevalent differences before the stroke.

\section{LOVIS CORINTH}

By 1901 Lovis Corinth (1858-1925) was one of the most eminent German painters. Art historical labels, however, are not easily applied to Corinth's works (Kuhn, 1925; Schröder, 1992; Blanke and Ortigue, 2011). He painted naturalistic portraits, slaughterhouse scenes as well as interiors, still lives and landscapes that link him to Impressionism. At the same time he produced history paintings illustrating biblical and mythological scenes upon which his reputation in the last decade of the nineteenth century was based. Although he rejected Expressionism in principle, most of Corinth's later works place him among the Expressionists (Schröder, 1992). His work thus defies easy categorization. Two major periods have preoccupied art historians: Corinth's mature, "impressionistic" period or style (1900-1911) and his late "expressionistic" style (1912-1925) starting with his right hemispheric stroke in December 1911.

Art critic Alfred Kuhn defined Corinth's paintings carried out after 1911 as the "Altersstil [or late style] of the painter." He commented that "the preponderance of the plastic and corporeal starts to disappear progressively" and "an essentially plane-like painterly seeing was appearing" (Figure 2A). Schröder (1992) describes Corinth's work as paintings in which "the balance between horizontal and vertical seems disturbed," as "unstable" and "tilting" paintings (Figure 2B). This is opposed to Corinth's mature style that was characterized by high levels of corporeality, richly nuanced flesh of the human body in figure and history paintings (Figures 2C,D) that made Corinth famous. The importance of depth and spatial relations were seen as the "Bravourelements" of his art (Kuhn, 1925; Schröder, 1992). Kuhn (1925) explicitly mentions Corinth's disease as an important factor in this artistic change (as does Uhr, 1990) whereas others disapprove of disease related medical accounts (Osten, 1955), all agreeing that Corinth's late style begins in early 1912 .

In December 1911, Corinth suffered a stroke and was immediately hospitalized although there seem to be no medical records. Corinth suffered from left-sided motor deficits of arm and leg and probably left-sided lower visual field deficits. After hospital discharge, he was able to walk a few steps, but only when supported by his wife and a cane. Although the right-handed Corinth already drew on his hospital bed, for several months she was not able to hold neither palette nor brushes in his left paretic hand. He recovered progressively and in 1914 his son noted that his father was again able to swim and walk without help. Based on these symptoms and several drawings that Corinth carried out in 1912, Jung (1974) proposed that he suffered from left-sided visuo-spatial HN. He also noted left-sided omissions in Corinth's post-stroke self-portraits. Thus, the central portrait shown in Figure 2E depicts Corinth's wife Charlotte to which Corinth added two self-portraits. Left-sided omissions can also be seen in Charlotte's face, her forehead and her hair. Her left shoulder was replaced by a small self-portrait. Although her left hand 


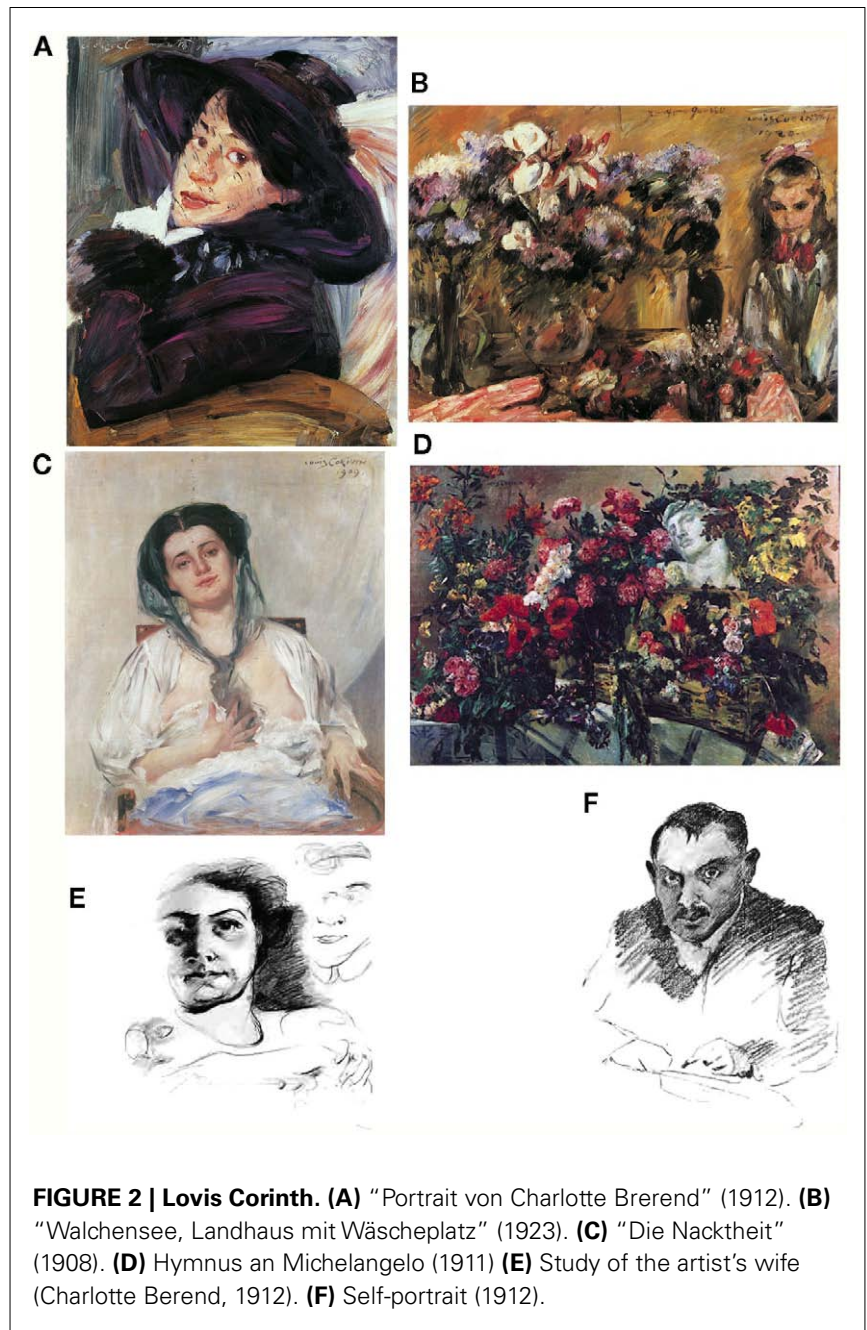

and arm are drawn, both show signs of spatial deformities and are less precisely drawn than the corresponding right body parts. It has also been observed that her left hemiface is less wide and drawn with less spatial detail and nuances (Blanke, 2006). Corinth's selfportrait on the right side also shows left-sided neglect suggesting the presence of object-centered graphic neglect. Thus, despite placing this self-portrait in his preserved right spatial field, Corinth omitted left facial features (eye, hair, left facial contour), suggesting the presence of an attentional-spatial deficit as opposed to sole perceptual-visual deficits such as hemianopia or quadranopia. The left self-portrait also shows left-sided graphic neglect (left eye and other left facial features are missing). In a later self-portrait (from 1912, Figure 2F) further left-sided omissions can be seen (Blanke, 2006).

HUGUETTE BOUCHARDY, ANTON RÄDERSCHEIDT, AND LOVIS CORINTH The association of left-sided omissions and a deviation of the entire drawing and painting toward the right has been described in six painters suffering from left-sided visuo-spatial HN (Blanke and Ortigue, 2011). Left-sided deformations and perseverations have also been observed. Characteristic deformations are shown in Figure $\mathbf{3 A}$ in a drawing by Bouchardy-Rey where we see that

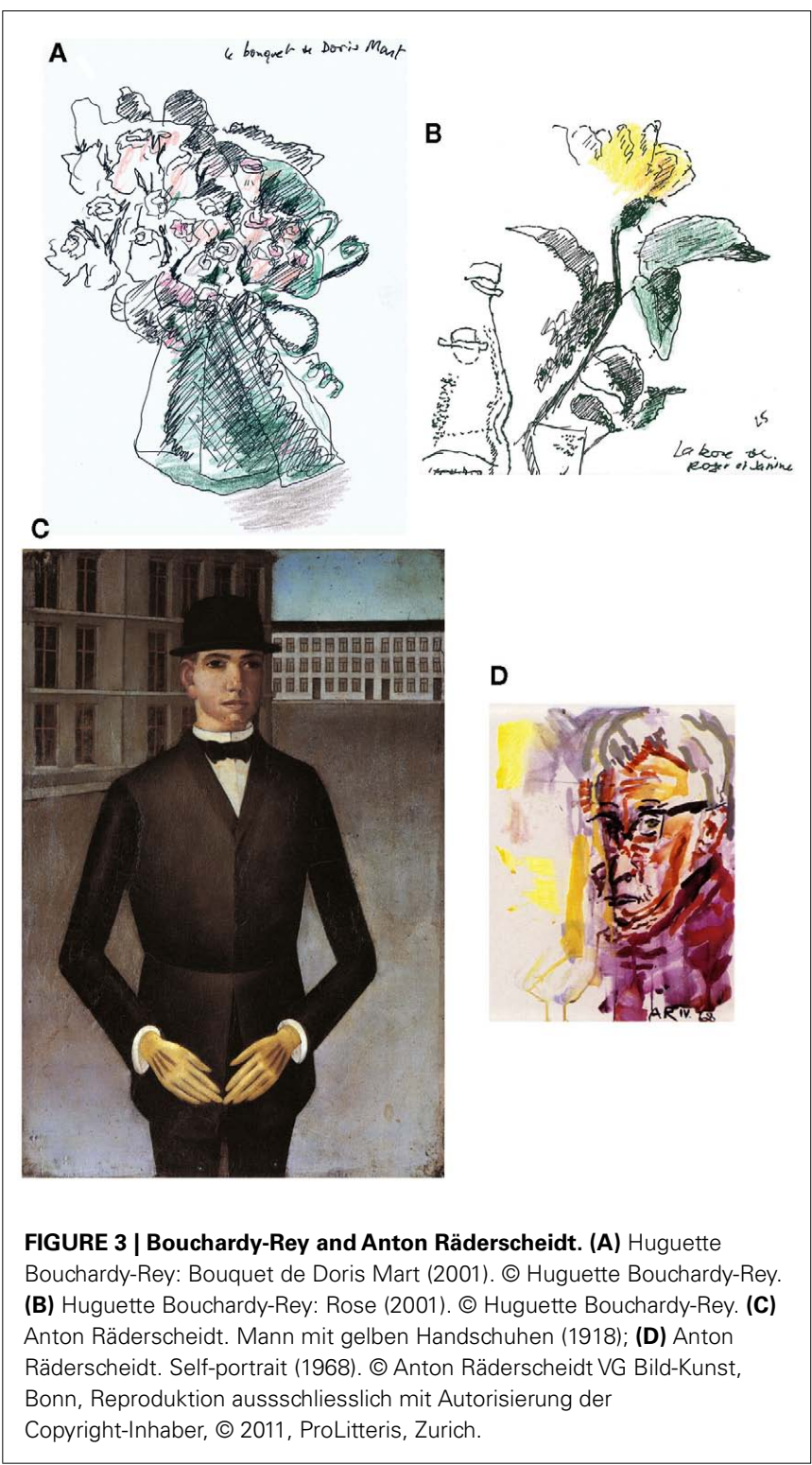

the roses on the left side of the bouquet are deformed or items drawn twice (perseverated) whereas this is absent for roses on the right side. Moreover, these classical elements of graphic $\mathrm{HN}$ have been postulated to give rise to a new style element in post-stroke paintings. Deformations, perseverations, and left-sided omissions and displacements lead to missing contours leading to an increase in flatness and loss of spatiality in post-stroke drawings and paintings by painters with HN (Blanke and Ortigue, 2011). In addition, objects and people are less clearly separated or distinguished from the environment and among themselves leading sometimes to a super-positioning of people and objects (sometimes due to perseverations; Figure 3B; see bottle on lower left). These elements may predominate on the left side of the painting, but can also be found over the entire canvas and have been described in works by Räderscheidt, Corinth, Alder, and Bouchardy (Blanke and Ortigue, 2011). As in the case of object-centered $\mathrm{HN}$ in Corinth, we stress the point that these latter findings underline the attentional (and 
not only perceptual) changes in these visual artists. These changes are thus independent from the loss of low-level visual deficits that may or may not exist in these artists, but rather relate to higherlevel attentional changes related to perceptual, representational, and/or motor aspects of visuo-spatial HN. Future work in painters with neglect should carefully determine what type of neglect the painter suffers from and evaluate the respective effects on the art works. Comparative studies should also be carried out in nonartist patients with visuo-spatial $\mathrm{HN}$, extending earlier work on drawing in patients (Piercy et al., 1960).

Art critic Kuhn has remarked in 1925 for Corinth's post-stroke works: "the contours disappear, the bodies are often as if pulled apart, deformed, their spatial relationships distorted, as if this would not be important anymore (as in Corinth's work before 1912)." We argue that these style changes are caused by the painter's altered mechanisms of attention, most likely related to the representation and the perception of "space" due to visuospatial HN. Whether these are the changes beholders of artworks find particularly remarkable may be another point of interest to pursue Berlyne (1954). Did these changes in the artist Corinth lead to the further development of his artistic "style" - from his Impressionism to his Expressionism- that is so characteristic of his later works (see Blanke, 2006; Blanke and Ortigue, 2011)? Surely this may not be regarded as the only reason for his late expressionistic phase, but it may well be an important reason, which brought him to paint in a way that in principle he himself did not value highly.

Although Corinth's paintings do not reveal clear signs of leftsided visuo-spatial HN, Blanke (2006) has argued that Corinth also changed his body position in front of the mirror when painting self-portraits, thus deviating from his customary stance (and that of his much admired Dutch masters Frans Hals and Rembrandt). In his self-portraits before 1912 Corinth depicts his body as turned rightward, whereas after 1912 he depicts himself mostly as turned leftward. Blanke (2006) has argued that this change in stance was necessary in order to look at his mirror reflection within his preserved right visual and spatial field avoiding his left neglected visual field (contrary to his pre-stroke habits).

Painters with visuo-spatial HN have also changed the palette of colors using colors differently, more intensely, and also more frequently as in their pre-stroke works. This is apparent in Corinth's "Walchensee" series where his color palette evokes those of his contemporary expressionists (such as Emil Nolde, Ludwig Kirchner, Franz Marc). Important changes in the use and perception of color have also been noted in Bouchardy-Rey (Blanke et al., 2003). Räderscheidt even describes in his diary that he experienced a "color explosion" ("Farbeinbruch") after his stroke, wondering, how he could have drawn for most of his life without much color. In fact, Räderscheidt is well-known for paintings from his magical realism period (1920s) that are characterized by cold, hard, and metallic colors such as gray, black, green and blue (Figure 3C). This is different in post-stroke paintings where he also uses intense reds and orange (Figure 3D). What is most relevant for the present considerations is that despite the original or mature style of the painter, country of origin, cultural background or epoque during which he or she was living there exists an ensemble of style elements that can be found in all of the affected painters. To us this suggests a common origin: interference with visuo-spatial mechanisms in the right brain that are crucial for the perception, representation, and making of paintings and drawings.

\section{FILM}

How does visuo-spatial $\mathrm{HN}$ affect filmmaking? Are there any filmmakers that have suffered visuo-spatial $\mathrm{HN}$ and continued to make films? The great film directors Federico Fellini and Luchino Visconti both suffered right hemispheric brain damage due to vascular stroke. Whereas Fellini was examined in detail in neurology, neuropsychology, and neuroradiology, equivalent data are not available for Visconti. Unfortunately, Fellini was not able to resume his cinematographic work, whereas Visconti made two major films after his right hemispheric stroke.

\section{FEDERICO FELLINI}

At the age of 73, in August 1993, the great cineast Federico Fellini (1920-1993) suffered right posterior brain damage associated with left visuo-spatial HN (Cantagallo and Della Sala, 1998). Fellini was also a great draftsman (De Santi, 1982) and showed several of the graphical HN signs that we described above for Corinth, Räderscheidt, and Bouchardy-Rey. Magnetic resonance imaging revealed a right temporo-parietal lesion compatible with vascular stroke. This was associated with a moderate sensorimotor left-sided deficit and left inferior quadranopia. Fellini's neuropsychological examination revealed normal language, face perception, long-, and short-term memory. The examination found left-sided visuo-spatial $\mathrm{HN}$ and severe visual extinction of which Fellini was only partially aware (Cantagallo and Della Sala, 1998). HNrelated omissions were found in cancelation and line bisection tasks (Figure 4A), complex figures and in writing and reading. These signs were only found in the early phase of hospitalization with normalization of performance in all tasks within 2 months. In reference to the graphical changes related to $\mathrm{HN}$ symptoms as described above, here, we depict two small drawings by Fellini revealing the presence of left-sided visuo-spatial HN (Figure 4B). Whereas these sketches are unmistaken recognizable as Fellini's,

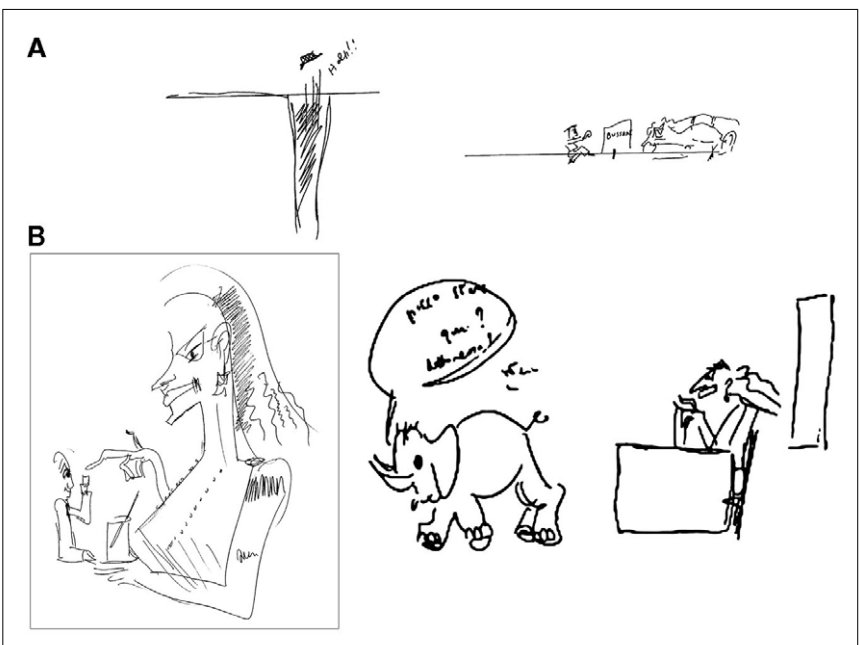

FIGURE 4 | Federico Fellini. (A) Two line bisections and Fellini's additions. (B) Two drawings from memory. With permission from Cantagallo and Della Sala (1998) @ 2011, ProLitteris, Zurich. 
there are many left-sided omissions and spatial deformations that were not present in his pre-stroke drawings (Cantagallo and Della Sala, 1998). Fellini was not able to resume his film work because he suffered a second vascular stroke, from which he died in October 1993.

\section{LUCHINO VISCONTI}

Luchino Visconti (1906-1976), the famous director of film, theater, and opera, suffered right brain damage at the age of 66 in August 1972. Just the same as Fellini he was a major figure of neorealism (Ferrara, 1963; Guillaume, 1966; Sterling, 1979). Visconti's work has been described as the translation of human subjectivity into a visual style (Nowell-Smith, 2003). Visconti was particularly famous for the decor of his film sets, which were painstakingly researched and reconstructed by a team of expert artists and craftsmen, the so-called "bottega viscontiana," under closest supervision of Visconti for reasons of authenticity (Schifano, 2009). A student of Visconti, Michelangelo Antonioni, remarks that spatial organization was a key aspect of Visconti's cinematographic work. He filmed with an immense accuracy in embedding the actor and making the actor adhere to the space, turning the immediately surrounding, peripersonal space into the actor's place of work (Lagny, 2002). The importance of spatiality in Visconti's cinematography is also commented in Schifano's (2009) biography. One important technique for achieving this spatial essence was, next to the use of a theatrical scenography, his use of locating objects and actors with respect to three cameras within space (Figure 5A). Another exceptional feature that contributes to the sense of spatiality and temporality in his films is the use of the cross-fade technique. In the cross-fade the filmed background is dissolved from one frame to the next by introducing a new background motive. This technique allowed Visconti to evoke a more realistic impression of elapsing time and a more realistic narrative flow, as well as for Visconti's style a "characteristic lack of internal curtains," which would have been induced through the classical montage of scenes (Schifano, 2009). Although montage has been defined as the foundation of film art by Arnheim (1957) and not only in reference to silent film classics but also to the Italian Neorealist school Visconti preferred to avoid the use of montage as a tool. Cross-fade can be thus seen as a particular element engendering his realism, in that he avoided narrative "ruptures" or complex temporal constructions. In the same way Visconti introduced large panoramic shots, uncut and of considerable length, by implementing dramatic spatial sequences used to describe the film location in relationship to a thematic spatial and temporal presence of the actors (Lagny, 2002). Comparable to a theater scene the complete film scenes were filmed on site and in continuous shots within the limits of the original location (i.e. location filming) by the parallel use of one fixed and two mobile cameras following the actors step-by-step in the duration of the whole scene. These impressive panoramic shots were precisely oriented in space (Schifano, 2009; Figure 5A, Figure 6A left). In his early and pre-stroke oeuvre Visconti thus mastered the spatial and temporal adhesion of the filming angles, close-ups and panoramic views to the visual content of what may be called the total sequence of a movie. In filming, this enhanced visual comprehension can be seen as the main endeavor to convey a symbolic spatial depth to the beholder (Arnheim, 1957).

In midst of an intense filming period for "Ludwig," the righthanded Luchino Visconti suffered a right-hemisphere stroke. Schifano (2009) reports an initial sensation of weakness that was followed by involuntary and uncontrollable movements of Visconti's left leg that lead finally to left-sided motor weakness and hemiplegia that affected left arm and leg. He was immediately brought to a hospital in Rome where he remained for 2 weeks and was then transferred to Zürich University Hospital where he stayed for 2 months. We were able to find only a limited number of documents about Visconti's acute and chronic medical history and convalescence period. For this we have relied on reports and descriptions of his friends, family, and biographers and a few television appearances. Thus, Visconti suffered from severe left-sided arm, hand, and leg paralysis and likely also associated left-sided somatosensory deficits. Inspection of a filmed original interview (that was part of the BBC documentary "The Life and Times of Luchino Visconti," 2002) shows an interviewer sitting to the left

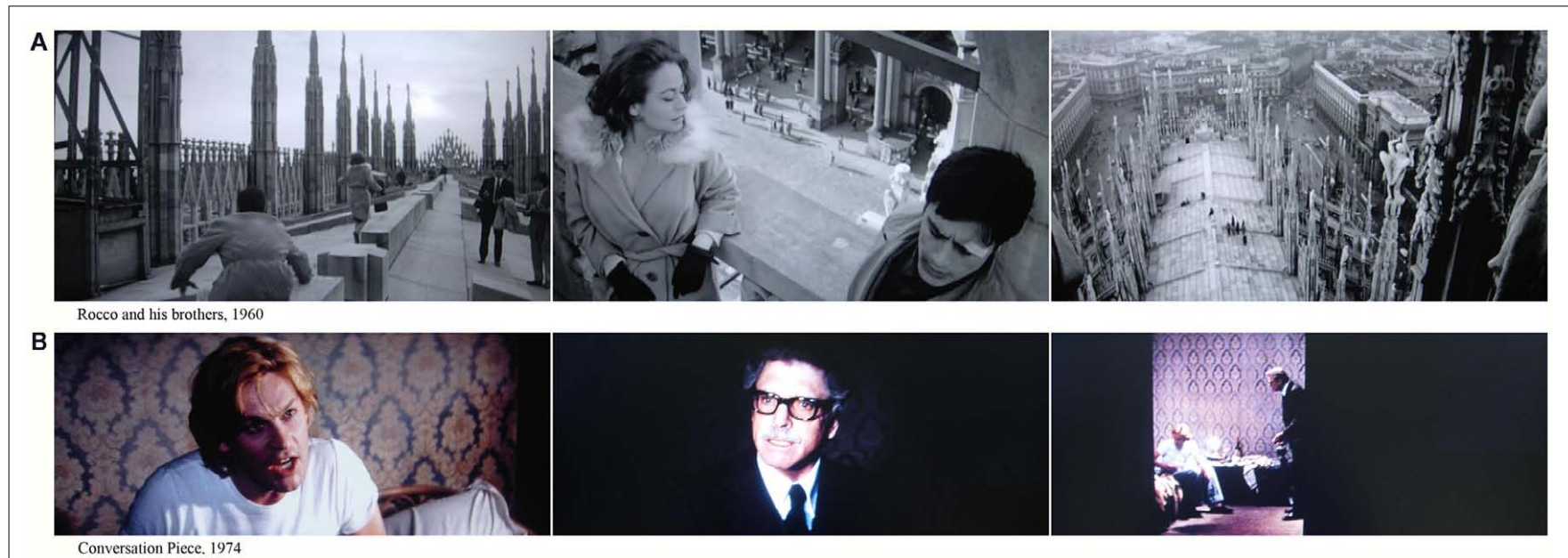

FIGURE 5 | Luchino Visconti. (A) Scene from "Rocco and his brothers" on top of the Dome in Milan. (B) Scene with sequence of close-ups in "Conversation Piece." ( 2011, ProLitteris, Zurich. 
of Visconti. Photographs taken from that period reveal the persistence of important motor impairments of the left upper and lower extremity. Our analysis revealed no major facial asymmetries and -concerning space exploration- no overt gaze or attention abnormalities toward the left side. These findings testify to Visconti's rapid recovery, despite the persistence of his left-sided motor deficits. It is reported that later on Visconti further recovered and was able to walk with the help of a cane and in 1975 able to walk and stand with the help of a cane (Dieguez et al., 2007; Schifano, 2009). The relative sparing of facial paralysis suggests that Visconti's brain damage may not have been (or not only) at the subcortical level (that most often affects the entire hemi-body), but more likely included cortical structures in right frontal and/or parietal cortex. Based on some lacking neurological, neuroradiological, and neuropsychological standard data and the normal responses and exploration of the $\mathrm{BBC}$ interviewer to Visconti's left side it is difficult to ascertain the diagnosis of left-sided visuospatial HN. Yet, as almost all patients with left-sided paralysis due to vascular right-hemisphere stroke (i.e., $82 \%$ in the study by Stone et al., 1993) suffer from left-sided HN, the presence of visuo-spatial $\mathrm{HN}$ in Visconti is more likely than its absence.

We compared Visconti's films with those of other filmmakers by employing terminology introduced by the late Arnheim (1957) and also by comparing his work with drawings and paintings by painters suffering from visuo-spatial HN. Although Visconti quickly resumed the abruptly stopped film montage of "Ludwig" we do not know how much work Visconti has carried out himself (the officially released version of the film is considered by many to have been under influence of others). We have therefore focused our preliminary analysis selected pre- and post-stroke films. Film critic Geoffrey Nowell-Smith comments that the "last two films ('Conversation Piece,' The innocent') were curious and puzzled his admirers as much as his detractors" (Nowell-Smith, 2003). Lagny (2002) writes that in "Conversation Piece" "everything resides in the intense reflection about space, which in the film is constructed rather through the exchange of glances than through shifts of place" and that "everything happens in closed rooms, which remain difficult to situate in relation to each others." Other film critics have mentioned Visconti's shift in filming technique, from Visconti's characteristic cross-fade of the pre-stroke period to the montage of close-ups on post-stroke films (Figure 5B). The montage of close-ups corresponds to a technical practice, which, in Visconti's pre-stroke filmography, was much less often adopted and, if so, mostly in combination with panoramic scenes. It seems that the late Visconti imposed these uncharacteristic close-ups against the will of his surprised crew with whom he had been working for decades [i.e., such as his long-time camera man Giuseppe Rotunno who proposed that Visconti's late and exacerbated use of the closeup was related to his stroke and paralysis (Schifano, 2009)]. We disagree with this medical proposal and conscious adaptation by Visconti and rather argue in the next paragraph for a stroke-related change in cognitive style in Visconti due to visuo-spatial HN.

To summarize, in the two post-stroke films, "Conversation Piece” of 1974 and “The Innocent” of 1976, Visconti employs closeups in a much more deliberate and independent way. Considering that in pre-stroke films these close-ups were rare and if present almost always embedded in longer and panoramic film sequences (with changing surroundings integrated through cross-fading), we suggest that this late - explicit, novel, and abundant use of the close-up (Figure 6) strongly impacted the spatial configuration, or cinematographic spatiality, in Visconti's last two films. Concerning close-ups Arnheim wrote that "a superabundance of close-ups very easily leads to (...) a tiresome sense of uncertainty and dislocation" and "a film artist will generally find himself obliged not to use close-ups alone but only in conjunction with long shots that will give the necessary information as to the situation in general" (Arnheim, 1957). This analysis suggests that the post-stroke affordance of the previously avoided close-up may be related to visuo-spatial $\mathrm{HN}$ that is classically associated with uncertainty and dislocation (Blanke and Ortigue, 2011). Again, as remarked for Corinth's change from his Impressionism to his late Expressionism, these unusual or untypical elements may be those that the beholders of artworks will find particularly remarkable (Berlyne, 1954).

Schifano (2009) detects a loss of spatiality in "Conversation Piece" and infers this as a style element of the late Visconti (Figure 5, Figure 6A,B). The artist himself describes the images of the interiors in his late film as "freely recomposed, in the total freedom of proportion and position" (Lagny, 2002). What we submit to our reader's opinion is that the visuo-spatial and attentional "deficits" associated with HN may have inspired and somewhat guided Visconti to adopt and develop a new art making as was also the case in several painters (Blanke and Ortigue, 2011). Many films by Visconti have been described as autobiographical, but "Conversation piece" in particular. Moreover, the scenes in both post-stroke films are often filmed with the characters facing the camera in a close-up, and not in a natural position in space, such as in "Senso," "The Leopard," “The Damned," or "Ludwig," where complex spatial positions of the cameras in the interior generate a spatial mosaic of first- and third-person perspectives within the rooms (Figures 6B,C right). There is also, like never before, a nested structure of flashbacks -the "inner curtains"-which the artist had so far avoided and disliked. Finally, Nowell-Smith (2003) noted that in the later films "an interest in the decorative in its own right" and the "potential of color film to render visual surfaces in different ways" had become a principal issue (Nowell-Smith, 2003; Figure 6E). This can particularly be seen in the film "The Innocent" of 1976, Visconti's last cinematographic work.

\section{DISCUSSION}

Based on the preliminary analysis of Visconti, we propose that the following four elements are characteristic of the post-stroke versus the pre-stroke oeuvre of Visconti. First, he shifted from a spatio-temporally "realistic" perspective induced by filming the entire scene sequence in a realistic way within the real location's limits (location filming with few close-ups mostly embedded into large filmic panoramas and the use of cross-fades) to a constructed "space of glances" by frequently deployed sequences of close-ups and more static perspectives. This was, second, associated with topographical and architectonic spatial disruptions, as opposed to his famous clarity for a cinematographic space. Third, in the poststroke films the actors much more often face the camera frontally generating the impression of flatness of bodies, scenery, and room sequence, compared to the pre-stroke films where perspectival 
A

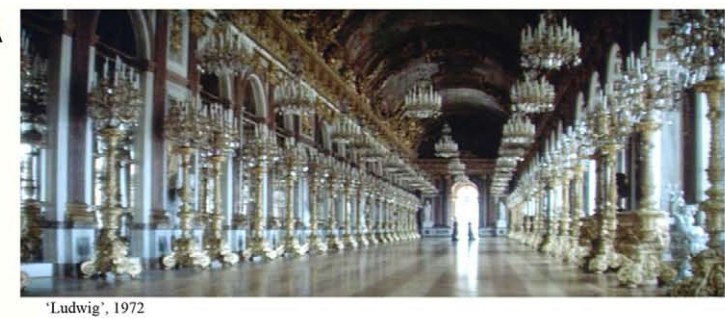

B

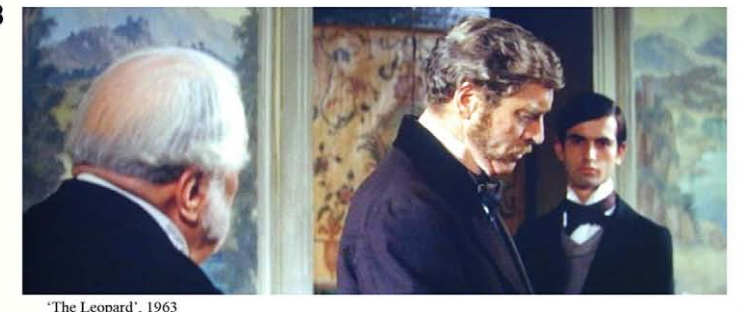

C

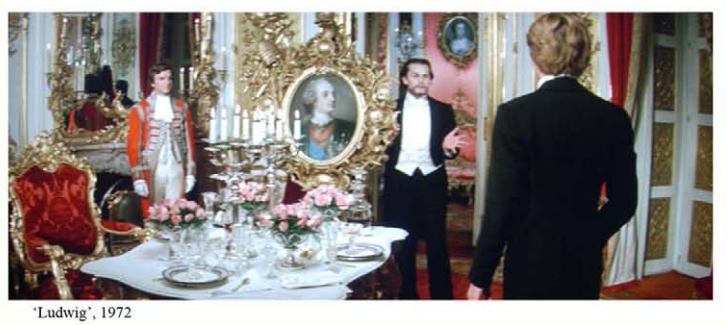

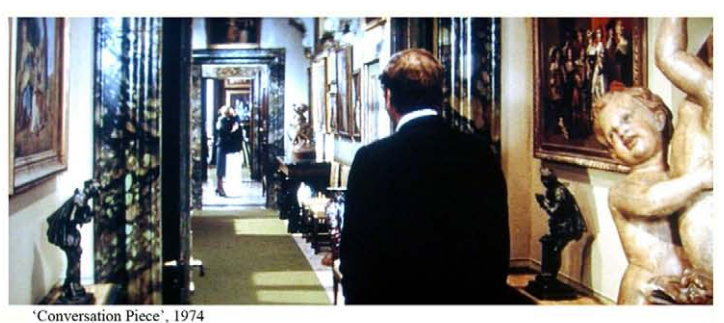

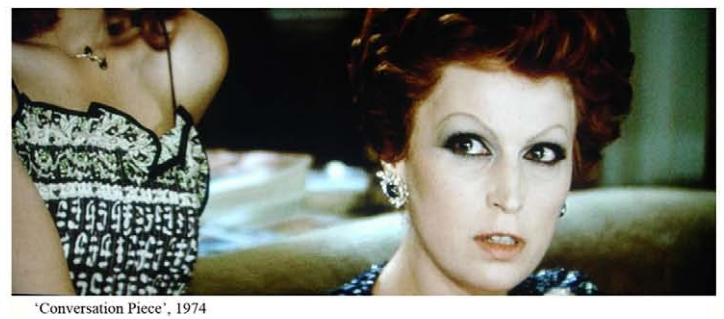

'Conversation Piece', 1974

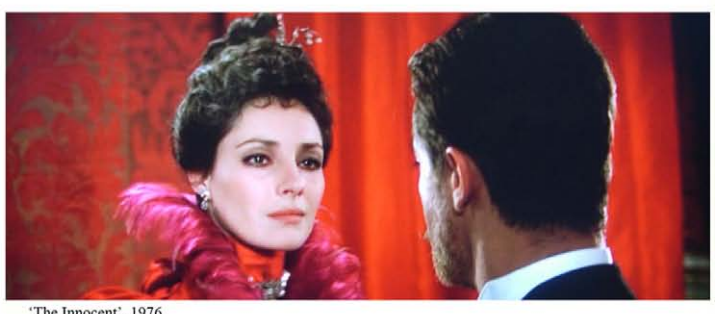

'The Innocent', 1976
FIGURE 6 | Luchino Visconti. (A) Representation of space in "Ludwig" (left) and in "Conversation Piece" (right). (B) Spatial complexity of gaze and perspective in "Leopard" (left) and in "Conversation Piece (right)." (C) Color in "Ludwig" (left) and in "The innocent" (right). (c) 2011, ProLitteris, Zurich. changes as well as richness and clarity of space and figures are more prevalent and render a more complex spatial configuration. Finally, there is a heightened interest in color and surface rendering in the late Visconti.

These Viscontian post-stroke elements are also present in the post-stroke artworks of painters with visuo-spatial HN. Thus in Corinth- next to more directly related HN signs such as leftsided omissions and deformations -his post-stroke oeuvre is also characterized by a plane-like way of painting. These paintings have been described as less spatial and corporeal, as containing spatially deformed elements (Kuhn, 1925). We described above how this differs dramatically from Corinth's pre-stroke works for which he was famous. In fact, the beautiful depiction of depth and spatial relations between objects, people, and environment were seen as the key elements of Corinth's art; as for Visconti. Thus, both artists - despite their difference in genre, epoch, and individual styles - moved away from their strong reliance on spatiality to a visual art where "the contours disappear, (...) the bodies are often as if pulled apart, deformed, their spatial relationships distorted, as if this would not be important anymore". Much alike, in his work on cinematography and time, Deleuze (2007) comments on the articulation of Visconti's main characters in his last film: "Everything becomes confused, to the point of indiscernibility of the two women in 'The Innocent.". Closeup and frontality characterizes the portrayed protagonists in the post-stroke works of Visconti and Corinth enhancing the desired distortion and planelikeness of the person in the painted or filmed environment. The changed and enhanced rich use of color and textures and its importance in enchanting the spatial relationships between person, object, and environment is a further factor that merits attention. We believe it is present in the post-stroke works of Visconti, Bouchardy, Räderscheidt, and Corinth in similar ways. The use of color (and the decorative) and its artistic employment in film was a great challenge that had to be faced by film artists in this time (Arnheim, 1957). Indeed, NowellSmith (2003) noted the different use of color and texture in Visconti's post-stroke films. Whereas, such remarks are difficult to link directly to visuo-spatial HN, we note that Kuhn (1925) and Uhr (1990) had remarked comparable changes in the post-stroke paintings of Corinth. Also Räderscheidt mentioned in his autobiography his own heightened interest in color in his post-stroke works (Blanke and Ortigue, 2011). These post-stroke similarities suggest that the study of visual artists with visuo-spatial $\mathrm{HN}$ may allow us to formulate new questions about color and the visual arts.

How much were the discussed artists aware of these changes? We believe with Dieguez et al. (2007) that Visconti and the other artists were well aware of these changes (as well as of their sensorimotor impairments). Yet, awareness does not exclude that $\mathrm{HN}$ will influence drawings and artworks as shown for Fellini (Cantagallo and Della Sala, 1998) and Bouchardy-Rey (Blanke and Ortigue, 2011). Visconti and Corinth may have taken this 
to a new level in art by creating masterpieces of striking beauty for many years with their HN. More work is necessary concerning automaticity and awareness in art making, an issue that should fascinate scholars of consciousness alike. We think that comparative analysis about awareness in Fellini and in other visual artists will be one interesting avenue to pursue. For example, Fellini wrote in a drawing "Cos'è sinistra?" but omitted to draw left-sided picture elements in that same and many other drawings (Cantagallo and Della Sala, 1998). This illustrates how the role of consciousness and awareness in art making may be studied empirically at least in the early phase after the onset of visuo-spatial HN. This is an interesting topic that may allow to study some of the numerous ways of artistic freedom, creativity, and the role of consciousness and awareness in art making also in later phases and in art making in general.

The Brazilian filmmaker Glauber Rocha detected Visconti's tendency to frequently zoom into the picture (as well as other "late style" changes) already in Visconti's films from the 1960s'. He thus argued for a more continuous evolution toward his late style (i.e., focus on the close-up), describing them as Visconti's "healthy (and desired) rupture with Italian pictorial tradition” (Schifano, 2009). It may of course be the case. Yet, the above described similarities with painters and filmmakers and much earlier film critical writing about Visonti's late style would argue against Rocha's claim. Also, we cannot fail to remark that similar disagreement also characterizes art critics' opinions about the pre- and poststroke style in Corinth as well as Räderscheidt (Blanke, 2006; Blanke and Ortigue, 2011). Both, Visconti and Corinth, "pose a challenge to (...) criticism" as Nowell-Smith (2003) writes about Visconti. For both artists seems to apply what Schröder (1992) writes about Corinth: "There were no problems to distinguish (...) the mature period (...). The helplessness begins when trying to describe Corinth's late works. Already where it belongs is debated. Is it expressionistic? Or did it remain to the end consequently impressionistic?" A way to avoid this difficulty, as our analysis suggests, is to link some of these changes to visuo-spatial

\section{REFERENCES}

Alajounaine, T. (1948). Aphasie and artistic realization. Brain 71, 229-241.

Arnheim, R. (1954). Art and Visual Perception. A Psychology of the Creative Eye. Berkeley: California University Press.

Arnheim, R. (1957). Film as Art. Berkeley: University of California Press.

Bänzer, H., and Hennerici, M. (2006). Stroke in painters. Int. Rev. Neurobiol. 74, 165-191.

Berlyne, D. E. (1954). A theory of human curiosity. Br. J. Psychol. 45, 180-191.

Bisiach, E., and Luzzatti, C. (1978). Unilateral neglect of representational space. Cortex 14, 129-133.

Blanke, O. (2006). Visuo-spatial neglect in Lovis Conrinth's selfportraits. Int. Rev. Neurobiol. 74C, 193-214.
Blanke, O., Forcucci, L., and Dieguez, S. studying perception of art. Nature $462,984$.

Blanke, O., and Lenggenhager, B. (2007). "Neuropsycologische Grundlagen der Malerei. Neglekt-bedingte Stilelemente in Lovis Corinths Kunst nach 1912," in Psychiatrie und Kunst - Interdisziplinäre Studien Bormuth, K. Podoll, and C. Spitzer (Göttingen: Wallstein Verlag), 147-180.

Blanke, O., and Ortigue, S. (2011). Lignes de fuite. Vers une neuropsychologie de la peinture. Lausanne: Presses Polytechniques Universitaires Romandes.

Blanke, O., Ortigue, S., and Landis, T. (2003). Colour neglect in an artist. Lancet 361, 264 (2009). Don't forget the artists when zur Künstler Pathographie, eds M.

HN. We want to be careful, to avoid being misunderstood: as we have argued before (Blanke, 2006) artists will transcend these neuropsychological difficulties and have gone on to create artworks, masterpieces of amazing complexity and beauty. It is also true that their post-stroke works remain unmistakingly a Visconti or a Corinth. Yet we insist: the presence of visuo-spatial HN following right brain damage may have played an important (and empirically testable) role in the predominance of the respective developments, leading to a common late style in these different artists. As stated by Ernst Gombrich concerning the categorization of style, "it is impossible to lay down [artistic] rules. . .because one can never know in advance what effect the artist may wish to achieve" (Gombrich, 2006). We would like to add that the presence of visuo-spatial HN in some unfortunate artists such as Corinth, Bouchardy, Räderscheidt, Fellini, and Visconti may allow to study at least some of these aspects with respect to what is known about the right-hemisphere's role in perception and cognition.

We hope that these thoughts will be taken further and will also be applied to other visual arts such as sculpture and architecture (see Halligan and Marshall, 2001 for sculpture) and of course to more recent forms of the visual arts that are currently unexplored. In addition this needs to be combined with laboratory studies with visual artists as subjects in standardized experiments (see also Blanke et al., 2009), as well as studies testing the role of the left versus right-hemisphere in perceiving, judging and making drawings and paintings. One promising line of research is work by Dahlia Zaidel and others (Levy, 1976; Regard and Landis, 1989; Zaidel and Kusher, 1989; Zaidel, 2006). These approaches may already be difficult to achieve for making of drawings and paintings, but will likely be even more demanding for filmmaking. In-depth analysis of the artworks of our selected painters and filmmakers, holds to our opinion also some answers to what visual arts are and what visual artworks are. Importantly, it may help building a bridge between art criticism and empirical science (such as neuropsychology and neuroscience) on our way toward more frequent trespassing.

Bonvicini, G. (1926). Die Aphasie des Malers Vierge. Wien. Med. Wochenschr. 76, 88-91.

Cantagallo, A., and Della Sala, S. (1998). Preserved insight in an artist with extrapersonal spatial neglect. Cortex 34, 163-189.

Cela-Conde, C. J., Agnati, L., Huston, J. P., Mora, F., and Nadal, M. (2011). The neural foundations of aesthetic appreciation. Prog. Neurobiol. 94, 39-48.

De Santi, P. M. (1982). I disegni di Fellini. Bari: Editori Laterza.

Deleuze, G. (2007). Cinema 2 - The Time-Image. Minneapolis: University of Minnesota Press.

Dieguez, S., Assal, G., and Bogousslavsky, J. (2007). Visconti and Fellini: from left social neorealism to right-hemisphere stroke. Front. Neurol. Neurosci. 22:44-74. doi:10.1159/000102871
Ferrara, G. (1963). Luchino Visconti, Cinéma d'Aujourd'hui, No 21. Paris: Editions Séghers.

Gardner, H. (1975). "The pathology of art," in The Shattered Mind: The Person After Brain Damage (New York: Vintage Books), 291-349.

Gombrich, E. (2006). The Story of Art. London: Phaidon.

Guillaume, Y. (1966). Visconti, Classiques $d u$ Cinéma. Paris: Editions Universitaires.

Halligan, P. W., and Marshall, J. C. (2001). Graphic neglect - more than the sum of the parts. Neuroimage 14, S91-S97.

Jung, R. (1974). "Neuropsychologie und Neurophysiologie des Kontur und Formensehens in Zeichnerei und Malerei," in Psychopathologie musischer Gestaltungen, ed. H. H. Wieck (Stuttgart: F.K. Schattauer Verlag), 27-88. 
Jung, R. (1975). "Compensation of visual neglect of the left side in right hemispheric lesions," in Cerebral Localization, eds K. J. Zülch, O. Creuzfeld, and C. J. Galbraidt (Berlin: Springer), 302-305.

Kerkhoff, G. (2001). Spatial hemineglect in humans. Prog. Neurobiol. 63, $1-27$.

Kris, E. (1952). Psychoanalytic Explorations in Art. Madison, CT: International Universities Press.

Kuhn, A. (1925). Lovis Corinth. Berlin: Propyläen Verlag.

Lagny, M. (2002). Luchino Visconti Vérités d'une Légende. Paris: Bibliothèque du Film/Durante.

Levy, J. (1976). Lateral dominance and aesthetic preference. Neuropsychologia 14, 431-445.

Nadal, M., and Pearce, M. T. (2011). The Copenhagen Neuroaesthetics Conference: prospects and pitfalls for an emerging field. Brain Cogn. 76, 172-183.

Nowell-Smith, G. (2003). Luchino Visconti. London: British Film Institue.

Ortigue, S., Megevand, P., Perren, F., Landis, T., and Blanke, O. (2006). Double dissociation between personal and extrapersonal neglect. Neurology 66, 1414-1417.
Osten G. von der. (1955). Lovis Corinth, Munich: F. Bruckmann Verlag.

Piercy, M., Hecaen, H., and de Ajuriaguerra. (1960). Constructional apraxia associated with unilateral cerebral lesions-left and right sided cases compared. Brain 83, 225-242.

Regard, M., and Landis, T. (1989). "Beauty may differ in each half of the eye of the beholder," in Beauty and the Brain, eds I. Rentschler, B. Herzberger, and D. Epstein (Basel: Birkhauser Verlag).

Rentschler, I. (1988). Beauty and the Brain. Basel: Birkhäuser.

Robertson, I. H., and Halligan, P. W. (2001). Spatial Neglect: A Clinical Handbook for Diagnosis and Treatment. East Sussex: Psychology Press.

Schifano, L. (2009). Visconti - Une vie exposée. Paris: Gallimard.

Schnider, A., Regard, M., Benson, F., and Landis, T. (1993). Effects of a right hemispheric stroke on an artist's performance. Neuropsychiatry Neuropsychol. Behav. Neurol. 6, 249-255.

Schröder, K. A. (1992). "Nähe und Ferne: Faktur und Ausdruck im Schaffen Lovis Corinths," in Lovis Corinth, ed. K. A. Schröder (Munich: Prestel), 8-35.

Sterling, M. (1979). A Screen of Time-A study of Luchino Visconti. New York: Harcourt.

Stone, S. P., Halligan, P. W., and Greenwood, R. J. (1993). The incidence of neglect phenomena and related disorders in patients with acute right or left hemisphere stroke. Age Aging 22, 46-52.

Uhr, H. (1990). Lovis Corinth. Berkeley: California University Press.

Verdon, V., and Vuilleumier, P. (2010). Neuroanatomy of hemispatial neglect and its functional components: a study using voxel-based lesion symptom mapping. Brain 133, 880-894.

Vigouroux, R. A. (1997). La fabrique $d u$ beau. Paris: Editions Odile Jacob.

Vigouroux, R. A., Bonnefoi, B., and Khalil, R. (1990). Réalisation picturales chez un artiste peintre présentant une héminégligence gauche. Rev. Neurol. 146, 665-670.

Zaidel, D. W. (2006). Neuropsychology of Art. Neurological, Cognitive and Evolutionary Perspectives. Hove, NY: Psychology Press.
Zaidel, D. W., and Kasher, A. (1989). Hemispheric memory for surrealistic versus realistic paintings. Cortex 25, 617-641.

Zeki, S. (2000). Inner Vision. Oxford: Oxford University Press.

Conflict of Interest Statement: The authors declare that the research was conducted in the absence of any commercial or financial relationships that could be construed as a potential conflict of interest.

Received: 18 April 2011; paper pending published: 14 August 2011; accepted: 13 November 2011; published online: 02 January 2012.

Citation: Blanke $O$ and Pasqualini I (2012) The riddle of style changes in the visual arts after interference with the right brain. Front. Hum. Neurosci. 5:154. doi 10.3389/fnhum.2011.00154

Copyright (C) 2012 Blanke and Pasqualini. This is an open-access article distributed under the terms of the Creative Commons Attribution Non Commercial License, which permits non-commercial use, distribution, and reproduction in other forums, provided the original authors and source are credited. 